\title{
A Highly Sensitive Label-free Aptasensor Based on Gold Nanourchins and Carbon Nanohorns for the Detection of Lipocalin-2 (LCN-2)
}

\author{
Chitra Padmakumari KuruP,* Noor Faizah MoHd-NAIM,** Chaker TLILI,*** and \\ Minhaz Uddin AHMED ${ }^{* *}$ \\ *Biosensors and Nanobiotechnology Laboratory, Integrated Science Building, Faculty of Science, \\ Universiti Brunei Darussalam, Jalan Tungku Link, Gadong, BE 1410, Brunei Darussalam \\ **PAPRSB Institute of Health Science, Universiti Brunei Darussalam, Jalan Tungku Link, Gadong, BE 1410, \\ Brunei Darussalam \\ ***Chongqing Institute of Green and Intelligent Technology, Chinese Academy of Sciences, Chongqing, China
}

\begin{abstract}
A synergistic nanocomposite film composed of gold nanourchins (AuNU), oxidised carbon nanohorns (CNH), and chitosan functioned as an electrode modifier in the fabrication of the sensitive lipocalin-2 (LCN-2) aptasensor. The AuNUs/CNH/CS composite increased the surface area and thereby amplified the signal transduction. The amineterminated LCN-2 aptamer was immobilised through the amide bond formed between the carboxyl group of polyglutamic acid (PGA) and the amine group of aptamer. Interaction of LCN-2 with the aptamer caused conformational changes in the structure of the aptamer. This generated higher conductivity, resulting in increased DPV peak current. The DPV signal increased with increasing concentration of LCN-2, and the change in signal was used for quantitative detection. The proposed aptasensor was able to detect LCN-2 in the linear range of $0.1-100.0 \mathrm{pg} \mathrm{mL}^{-1}$, with a low detection limit of $10 \mathrm{fg} \mathrm{mL} \mathrm{m}^{-1}$. The aptasensor showed high sensitivity, selectivity, reproducibility, and was able to detect LCN-2 in serum samples.
\end{abstract}

Keywords LCN-2, aptasensor, gold nanourchin, carbon nanohorn, electrochemical

(Received August 12, 2020; Accepted September 25, 2020; Advance Publication Released Online by J-STAGE October 9, 2020)

\section{Introduction}

Over the past years, different techniques have been put forward to detect low concentrations of proteins that have been identified as biomarkers for particular diseases from a given sample. Amongst the diagnostic methods developed, aptasensors have been recognized for their excellent specificity and affinity towards target molecules such as proteins, organic and inorganic molecule, and even whole cells. ${ }^{1}$ Aptamers are synthetic singlestranded DNA or RNA molecule selected by systematic evolution of ligands by exponential enrichment (SELEX), which is an in vitro process that eliminates the tedious cell culture procedures required in conventional antibody synthesis. ${ }^{2}$ Hence aptamers are advantageous over antibodies due to the low cost of production, high stability and a more convenient synthesis process. $^{3}$ The role of aptamers in clinical diagnostics, food safety, drug delivery, environmental analysis and biodefence are becoming highly significant as numerous aptasensors utilizing different detection techniques such as colorimetric, surface plasmon resonance, and electrochemical ${ }^{4}$ have been reported.

To further improve the sensitivity of the sensors, nanomaterials have been employed for signal amplification. ${ }^{5}$ Carbon nanomaterials have been extensively applied in the field of clinical biosensors due to their excellent mechanical strength, large surface area and outstanding electrical conductivity. ${ }^{6}$

$\dagger$ To whom correspondence should be addressed.

E-mail: minhaz.ahmed@ubd.edu.bn
The single-walled carbon nanohorns (SWCNHs) are similar to single-walled carbon nanotubes (SWCNTs) in many aspects. They are horn-shaped and composed of single-wall graphene sheets. Their diameter ranges from $2-5 \mathrm{~nm}$, and its length is about $40-50 \mathrm{~nm}$. Nearly $2000 \mathrm{SWCNHs}$ aggregate to form a dahlia-shaped structure of about $100 \mathrm{~nm}$ in diameter. ${ }^{7}$ Recently, SWCNHs have been in high demand as they are superior over carbon nanotubes (CNTs) and carbon nanocages as their synthesis is considered more cost-effective. The synthesis process is based on $\mathrm{CO}_{2}$ laser ablation of pure graphite at room temperature, thereby avoiding the toxic metal contamination, which in turn contribute to the electrochemical performance. ${ }^{8}$ $\mathrm{CNHs}$ are widely used as support framework on electrodes for biomolecule binding due to their strong adsorption properties and conductivity. ${ }^{9}$ It is observed that the nano-composite of SWCNHs and other metal nanoparticles improves the sensitivity of biosensors. ${ }^{10}$ Gold nanoparticles have also been quite popular due to their excellent electrochemical properties and their impressive track record in the modification of the working electrode. The main benefit of employing gold nanourchins is the increased surface area, thereby resulting in signal enhancement. ${ }^{11}$

There has been growing use of electropolymerization as a modification method as it requires only small amounts of chemicals, resulting in the quick formation of a homogenous membrane directly onto the nanomaterial modified electrode surface. ${ }^{12}$ Most of the polymers possess functional groups that act as support surfaces during immobilization of the biomolecule through covalent modification. ${ }^{13}$ Polymerized amino acids have 
become popular in recent years due to their ease of preparation and biocompatibility. Glutamic acid quickly gained attention beacuse direct electropolymerization from the monomer was possible and also because of the presence of numerous protonated carboxyl groups that can participate in covalent bond formation. ${ }^{14}$

Recently, lipocalin-2 (LCN-2), a 25-kDa secretory glycoprotein, emerged as a biomarker for a plethora of diseases including acute kidney injury, intestinal inflammations, neuropsychiatric lupus $^{15}$ and Alzheimer's disease. ${ }^{16}$ LCN-2 regulates multiple cellular functions, as it acts as a carrier and binds to specific receptors. Sequestering of iron-loaded bacterial siderophores by LCN-2 highlight its role in immune response. ${ }^{17}$ Over the years, a wide variety of analytical techniques has been developed to identify LCN-2. A couple of the conventional methods of detection are via western blotting ${ }^{18}$ and enzyme-linked immunosorbent assays (ELISA). Although they provide specific and sensitive data, they are rather laborious and expensive. Therefore, the development of more cost-effective devices is always desirable. Electrochemical biosensors are not only known for their low production cost but also for the quick, specific and sensitive analysis. Electrochemical biosensors that detect LCN-2 using antibodies have been previously reported. For example Yukird et al. developed a sensitive immunosensor by immobilizing antibodies on an electrosprayed graphene/polyaniline (G/PANI)-modified screen-printed carbon electrode. ${ }^{19}$ This study managed to phenomenally increased the oxidation current by 58 -fold when LCN-2 became bound to its antibody. Zhang et al. similarly reported a sandwich immunosensor modified with graphitic carbon nitride nanosheets $\left(\mathrm{C}_{3} \mathrm{~N}_{4}\right)$ deposited with the redox molecule Prussian Blue (PB) nanoparticles. ${ }^{20}$ Aptamers are propitious over antibodies as they can recognise a variety of target molecules, ranging from small to large proteins. They also bind with higher affinity and specificity due to the conformational changes in their threedimensional structure upon target molecule attachment. ${ }^{21}$ Therefore, aptamer-based assays, such as aptamer-linked immunosorbent assay (ALISA) and aptamer-based fluorescence assay have already gained some attention. Several aptamerbased studies have been reported for the detection of LCN-2. Matassan et al. detected picogram level of LCN-2 using a graphene-modified aptasensor, ${ }^{22}$ whereas Tiğ et al. reported a sandwich apatsensor with a wide linear range based on the poly3-amino-1,2,4-triazole-5-thiol/grapheneoxide composite (P(ATT)GO) and gold nanoparticles (AuNPs). ${ }^{23}$

Screen-printed electrodes (SPE) is increasing traction in the field of biosensors due to their inexpensive fabrication technique and convenient application. ${ }^{24}$ When coupled with electrochemical detection, these miniature sensors are competent enough for producing reproducible outcomes with high sensitivity. In this study, a novel nanocomposite was synthesized from gold nanourchins (AuNU), oxidized carbon nanohorns $(\mathrm{CNH})$ and chitosan (CS) in a single step. $\mathrm{CNH}$ and AuNU were chosen because both provided a large surface area to work on, and efficient aptamer immobilization to the electrode was noted as a result of the nanocomposite modification. To the best of our knowledge, this is the first study that used the AuNU/CNH/CS nanocomposite combination as an electrode modifier that consequently resulted in signal amplification. This lead to the fabrication of a sensitive label-free voltammetric LCN-2 aptasensor. CS is a cationic biopolymer that is known for its adhesive nature and its efficient film-forming ability as well as its high mechanical strength. ${ }^{25}$ Glutamic acid was electropolymerized onto the AuNU/CNH/CS layer by an amide bond between the $\alpha$ amino and $\beta$ carboxylic groups to increase the number of carboxylic groups on the electrode surface. ${ }^{26}$ The amine-terminated LCN-2 aptamer was adsorbed via amide bond to the carboxylic group of the polyglutamic acid layer using EDC/NHS chemistry. Quantitative detection of LCN-2 was monitored by detecting the current response obtained through differential pulse voltammetry (DPV) in the presence and absence of the LCN-2 protein.

\section{Experimental}

\section{Reagents and materials}

Oxidized carbon nanohorns and gold nanourchins were obtained from Sigma Aldrich. Recombinant LCN-2 protein was purchased from Sino Biological and reconstituted as instructed by the manufacturer. The $5^{\prime}$ amine-modified aptamer sequence was customised by IDT based on the previous literature: ${ }^{27}$

5'- $\mathrm{NH}_{2}$ ATACCAGCTTATTCAATTCGGAGGGCGGAAGCAAAGCGTAACAGAAAGC CAACA CGCGAGATAGTAAGTGCAATCT-3'

Chitosan (85\% deacetylated) was obtained from Alfa Aesar (Ward Hill, M.A). Potassium ferricyanide $\left(\mathrm{K}_{3}\left[\mathrm{Fe}\left(\mathrm{CN}_{6}\right)\right]\right)$, potassium ferrocyanide $\left(\mathrm{K}_{4}\left[\mathrm{Fe}\left(\mathrm{CN}_{6}\right)\right]\right)$, 1-ethyl-3-(3-dimethyl aminopropyl) carbodiimide (EDC), $N$-hydroxysuccinimide (NHS), potassium chloride $(\mathrm{KCl}), \quad 2$ - $(N$-morpholino $)$ ethanesulfonic acid (MES) buffer, bovine serum albumin (BSA), alpha fetoprotein (AFP), beta-2-microglobulin ( $\beta 2 \mathrm{M})$, haptoglobulin (HP), carcinoembryonic antigen (CEA), chitosan (CS) and glutamic acid (GA) were purchased from SigmaAldrich (St Louis, MO, USA). Commercialized $0.01 \mathrm{M}$ phosphate buffer saline (PBS) solution (containing $0.0027 \mathrm{M}$ potassium chloride and $0.137 \mathrm{M}$ sodium chloride, $\mathrm{pH}$ 7.4) was also supplied by Sigma Aldrich. The 0.01 M PBS was used for all dilutions and preparation of necessary buffers and washings. Preparation of $5 \mathrm{mM}\left[\mathrm{Fe}(\mathrm{CN})_{6}\right]^{4-13-}$ was carried out by mixing potassium ferrocyanide and potassium ferricyanide (1:1) in $0.01 \mathrm{M}$ PBS, and this functioned as the redox couple. Also, $1 \%$ bovine serum albumin (BSA) was constituted using $0.01 \mathrm{M}$ PBS. Each of the solutions were prepared with ultra-pure water from a Millipore-Milli-Q system. The chemicals used were all of analytical grade and all experiments were performed in triplicate (unless stated otherwise) $(n=3$, error bars represent the standard deviation) at room temperature $\left(20 \pm 1^{\circ} \mathrm{C}\right)$

\section{Apparatus and instruments}

All electrochemical measurements including cyclic voltammetry (CV) and differential pulse voltammetry (DPV) were performed using the Autolab potentiostat/galvanostat AUT302N coupled with NOVA software purchased from Metrohm Autolab (The Netherlands). The disposable three-electrode carbon micro screen-printed electrode (SPCEs, DEP-Chip EP-N) was purchased from Biodevice Technology, Japan. The DEP chip comprises the carbon working electrode, $\mathrm{Ag} / \mathrm{AgCl}$ reference electrode and carbon counter electrode. The total length and width of the DEP chip was 12 and $4 \mathrm{~mm}$ respectively, allowing it to work with small volumes of reagents and samples $(1-20 \mu \mathrm{L})$. The sample was first carbon-coated for $60 \mathrm{~s}$ before analysis using field-emission electron microscopy (FE-SEM) JEOL, JSM-7610F (Japan).

\section{Synthesis of AuNU/CNH/CS}

First, $2.5 \%$ chitosan solution was prepared in $1 \%$ acetic acid. Then, $0.5 \mathrm{mg} \mathrm{mL}^{-1}$ stock of $\mathrm{CNH}$ was prepared in the $2.5 \%$ chitosan and was sonicated for $2 \mathrm{~h}$ to achieve a uniform dispersion of the nanomaterial. To prepare the nanocomposite 


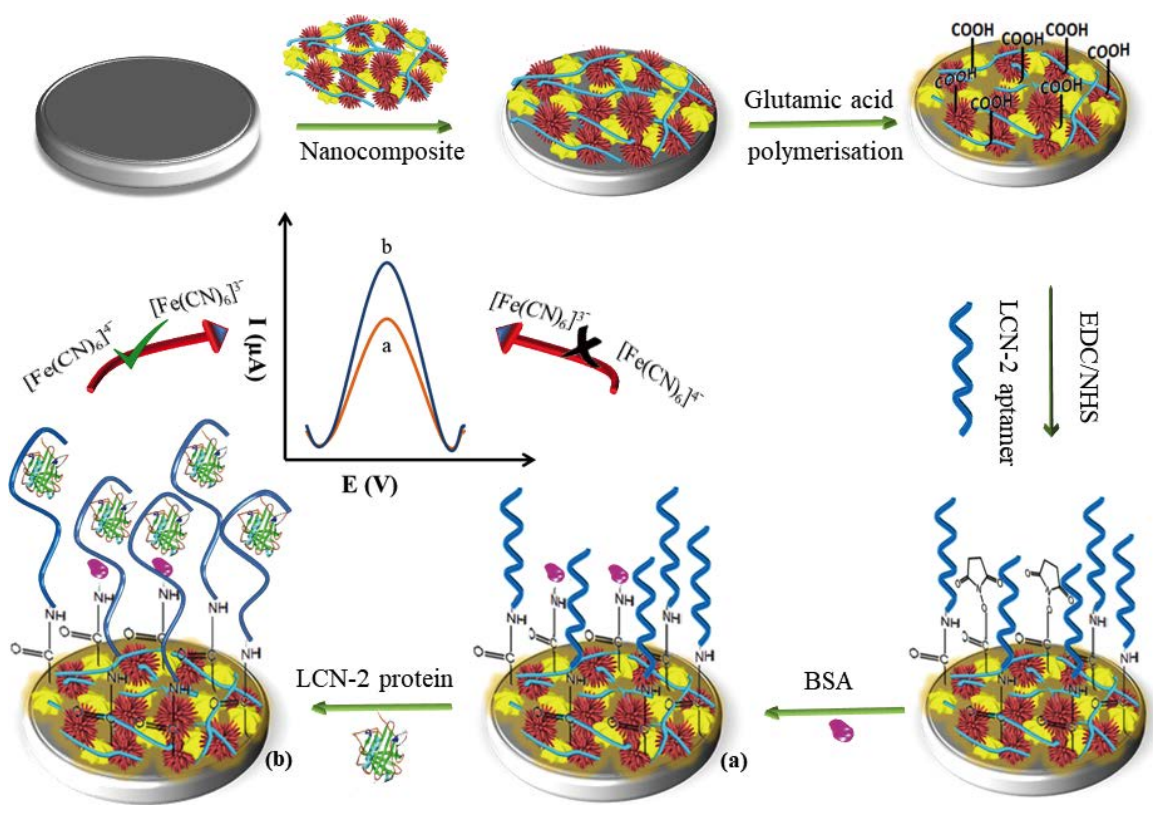

Fig. 1 Schematic representation of the fabrication steps of the LCN-2 aptasensor.

AuNU/CNH/CS, AuNU and CNH/CS were mixed in a volume ratio of $4: 1$, and then later stirred for $1 \mathrm{hr}$ before sonication for $2 \mathrm{~h}$. The prepared nanocomposite was stored at $4^{\circ} \mathrm{C}$ for further use.

\section{Fabrication of the LCN-2 aptasensor}

First, $3 \mu \mathrm{L}$ of AuNU/CNH/CS nanocomposite was dropcasted onto the working electrode of the SPCE and air-dried at room temperature for an hour. After the formation of the thin nanocomposite layer, the electrode was washed carefully with distilled water to remove any remnants of the unbound nanocomposite. This was then air dried at room temperature for the next modification step. The AuNUs/CNH/CS-modified electrode was electropolymerized with glutamic acid monomer according to the procedure described by Karaboğa and Sezgintürk $^{28}$ with slight modifications. Next, $2 \mu \mathrm{L}$ of $5 \mathrm{mM}$ glutamic acid prepared in $\mathrm{pH} 7.0$ phosphate buffer were dropped to cover all three electrodes. One cycle of cyclic voltammetry (CV) was applied at potential ranging from -0.8 to $+2.0 \mathrm{~V}$ at $50 \mathrm{mV} \mathrm{s}^{-1}$ to electropolymerize the glutamic acid (GA) onto the working electrode. The electrode was then rinsed with a copious amount of distilled water. The electrodes were incubated for $30 \mathrm{~min}$ at room temperature with $3 \mu \mathrm{L}$ of EDC/NHS in MES $(\mathrm{pH} 5.5)(1: 1(\mathrm{v}: \mathrm{v}))$ of $100 \mathrm{mM}$ EDC and $20 \mathrm{mM}$ NHS) to activate the carboxylic acid terminal groups of polyglutamic acid (PGA). They were then washed in PBS buffer and dried at room temperature. Subsequently, $3 \mu \mathrm{L}$ of $1 \mu \mathrm{M} \mathrm{mL}^{-1}$ of lipocalin aptamer (LCN-2 apt) was dropped onto the modified working electrode and incubated for $60 \mathrm{~min}$. The electrodes were then washed with $0.01 \mathrm{M} \mathrm{PBS}(\mathrm{pH}$ 7.4) to remove unbound aptamer molecules and dried at room temperature. Later, the modified electrodes were incubated with $1 \%$ BSA in $0.1 \% \mathrm{NaN}_{3}$ (w/v) solution for 45 min to block non-reactive ends and prevent non-specific interactions (as shown in Fig. 1). After the final washing and drying step, the manufactured aptasensor was stored at $+4^{\circ} \mathrm{C}$ until needed.

To detect the presence of $\mathrm{LCN}-2,3 \mu \mathrm{L}$ of $\mathrm{LCN}-2$ protein at a specific concentration was dropped onto the designed aptasensor and incubated for $30 \mathrm{~min}$ to allow for the formation of the aptamer-protein complex. Later, the electrode was rinsed with PBS to remove unbound LCN-2 molecules. Figure 1 shows the detection method of the proposed $\mathrm{LCN}-2$ aptasensor. As the target binds more $\left[\mathrm{Fe}(\mathrm{CN})_{6}\right]^{4-3-}$ redox molecules, they became attracted towards the electrode surface, resulting in a higher charge transfer. This is the detection principle behind the aptasensor. The increase in signal produced was proportional to the concentration of $\mathrm{LCN}-2$.

\section{Electrochemical measurements}

The interpretation of the layer-by-layer immobilization steps was conducted by cyclic voltammetry $(\mathrm{CV})$. The parameters for optimization of analytical performance of the aptasensor were evaluated using differential pulse voltammetry (DPV). CV and DPV were performed in $0.01 \mathrm{M}$ PBS ( $\mathrm{pH}$ 7.4) containing $5.0 \mathrm{mM} \mathrm{K}_{3}\left[\mathrm{Fe}(\mathrm{CN})_{6}\right] / \mathrm{K}_{4}\left[\mathrm{Fe}(\mathrm{CN})_{6}\right]$, and $0.1 \mathrm{M} \mathrm{KCl}$. Then, $3 \mu \mathrm{L}$ of varying concentrations of $\mathrm{LCN}-2$ was spiked onto the constructed aptasensor. After $30 \mathrm{~min}$ of incubation at room temperature, the aptasensor was later washed with PBS to remove any unbound protein. DPV was later used for analysis.

\section{Results and Discussion}

Characterization of AuNU/CNH/CS nanocomposite using scanning electron microscope (SEM)

The surface morphology and structure were observed by SEM as shown in Fig. 2. The bare SPCE was observed to have a flaky appearance as seen in Fig. 2A. Figure 2B shows the SEM image of bare SPCE modified with $\mathrm{CNH} / \mathrm{CS}$, which was seen to exist as spherical aggregates, while the AuNUs on the bare SPCE electrode (Fig. 2C) appeared star-shaped. In Fig. 2D, nanoparticles with distinct diameters can be observed, implying the presence of both $\mathrm{CNH}$ and AuNU.

\section{Electrochemical characterization of the nanocomposite}

To further substantiate the nanocomposite that will be used as the core component of the biosensor, a comparison study of the electronic conductivity of the nanocomplexes was performed using $\mathrm{DPV}$, with $5 \mathrm{mM} \mathrm{Fe}(\mathrm{CN})_{6}^{3-/ 4}$ containing $0.1 \mathrm{M} \mathrm{KCl}$ functioning as the redox probe. In Fig. 3A, the DPV plot of the (a) bare, (b) AuNU, (c) $\mathrm{CNH} /$ water, (d) $\mathrm{CNH} / \mathrm{CS}$, (e) AuNU/ 
(A)

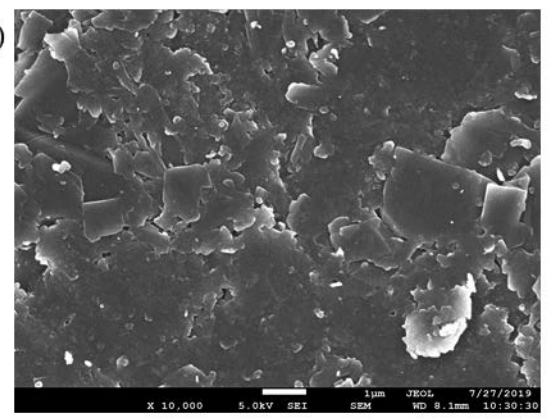

(C)

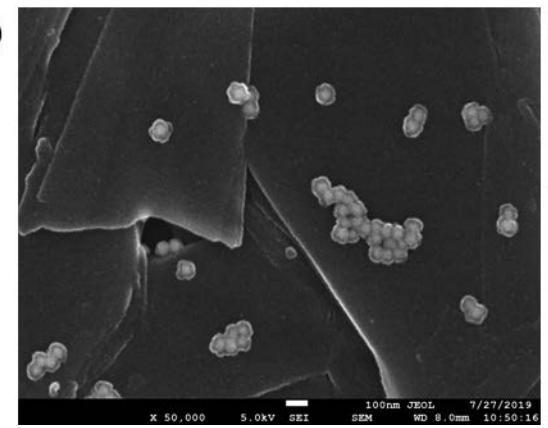

(B)

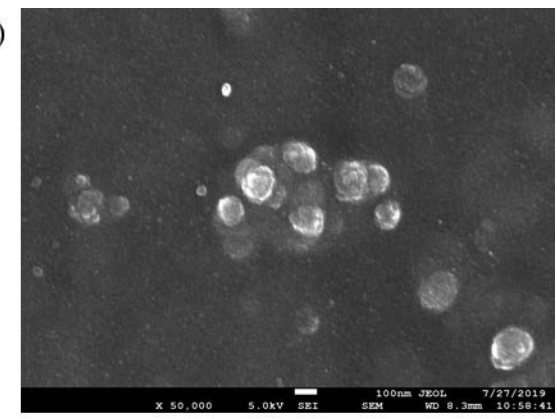

(D)

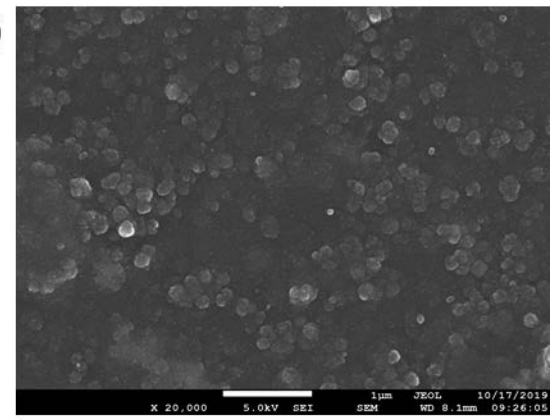

Fig. 2 SEM images of (A) bare SPCE, (B) CNH/CS, (C) AuNU, and (D) AuNU/CNH/CS.
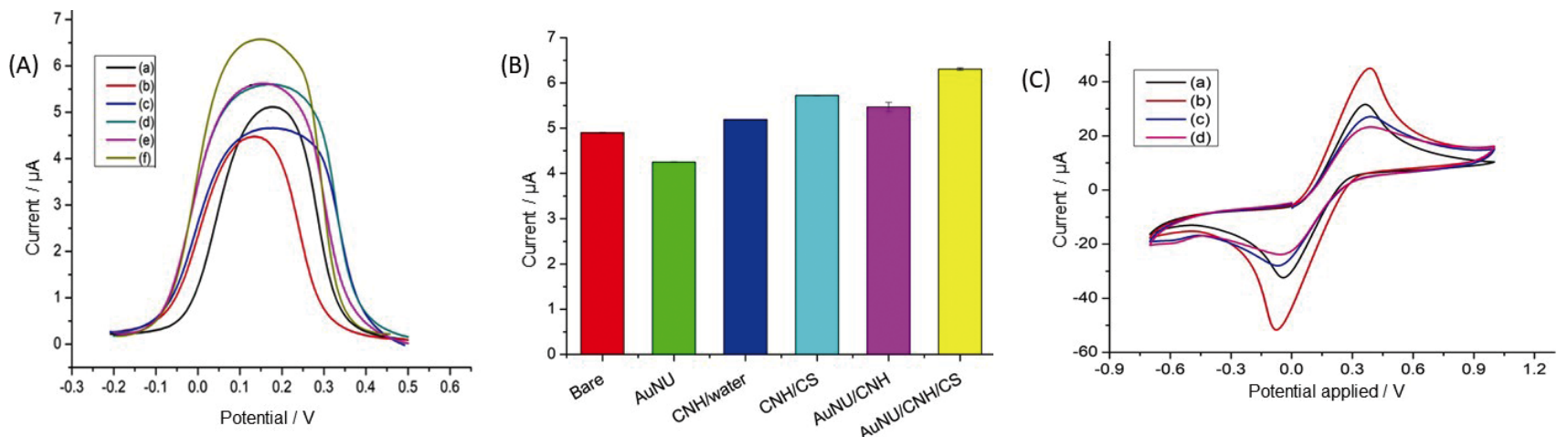

Fig. 3 (A) DPV curves of (a) bare, (b) AuNU, (c) CNH/water, (d) CNH/CS, (e) AuNU/CNH, and (f) AuNU/CNH/CS modified DEP chips. (B) Bar diagram of the DPV peak current of different nanomaterials/nanocomposites. (C) CVs of (a) bare SPCE, (b) bare/AuNU/CNH/CS, (c) bare/AuNU/ $\mathrm{CNH} / \mathrm{CS} / \mathrm{PGA}$, and (d) bare/AuNU/CNH/CS/PGA/Apt in $0.01 \mathrm{M} \mathrm{PBS}(\mathrm{pH} 7.4)$ containing $5 \mathrm{mM}$ $\left[\mathrm{Fe}(\mathrm{CN})_{6}\right]^{3-} /\left[\mathrm{Fe}(\mathrm{CN})_{6}\right]^{4-}(1: 1)$ and $0.1 \mathrm{M} \mathrm{KCl}$.

$\mathrm{CNH} /$ water and (f) AuNU/CNH/CS-modified DEP chips are displayed. From that, the DPV peak height comparison for the analyzed chips are shown as Fig. 3B. It is clear from Figs. 3A and $3 \mathrm{~B}$ that the AuNU/CNH/CS-modified electrode achieved the maximum signal amplification corresponding to the highest peak current. This reflected the excellent electronic conductivity of the AuNU/CNH/CS and correlated with the increased surface area provided by the combination of AuNUs and CNHs.

\section{Electrochemical characterization of the aptasensor}

In this study, the electrode was modified using AuNU/CNH/ CS and PGA to increase the surface area for aptamer immobilization. The introduction of PGA layer could reduce the $\pi-\pi$ interaction between the aptamer and the nanocomposite surface, with the aptamer binding to the surface of the PGA modified layer via the amide linkage. The electrodes were then characterized by $\mathrm{CV}$ and were recorded from -0.7 to $1.0 \mathrm{~V}$ in $5 \mathrm{mM} \mathrm{Fe}(\mathrm{CN})_{6}^{3-14}$ containing $0.1 \mathrm{M} \mathrm{KCl}$ at a scan rate of
$100 \mathrm{mV} / \mathrm{s}$. Furthermore, the modified electrodes were additionally characterized using DPV (Fig. S1, Supporting Information). From Fig. 3C, it can be seen that the bare SPCE (curve a) exhibited a pair of well-defined reversible redox peaks, suggesting that a quasi-reversible electrochemical process was taking place. After the AuNUs/CNH/CS nanocomposite was dropped, an elevated peak current was observed (curve b) due to the synergistic amplification effect of the nanomaterials used. This was analyzed by applying the Randles-Ševćik equation ${ }^{29}$ to calculate the electroactive surface areas (denoted as A) of the bare electrode and the nanocomposite modified electrode.

$$
I_{\mathrm{p}}=2.65 \times 10^{5} n^{3 / 2} A D^{1 / 2} V^{1 / 2} C
$$

Where $I_{\mathrm{p}}$ is the peak current, $n$ is the number of transferring electrons, $A$ is the electroactive area $\left(\mathrm{cm}^{2}\right), D$ is the diffusion coefficient $\left(6.7 \times 10^{-6} \mathrm{~cm}^{2} / \mathrm{s}\right),{ }^{30} V$ is the scan rate, and $C$ is the concentration of the electroactive species. Five SPCEs were 
modified with the AuNU/CNH/CS nanocomposite and the electroactive surface areas were calculated individually for each of them (Fig. S2). The electroactive surface area was found to be $4.1 \mathrm{~mm}^{2}$ for the modified electrode and $2.6 \mathrm{~mm}^{2}$ for the unmodified electrode. This supported the fact that the AuNU/ $\mathrm{CNH} / \mathrm{CS}$ nanocomplex increased overall conductivity due to the increased surface area provided by both AuNU and $\mathrm{CNH}$. Additionally, the diffusion kinetics of the nanocompositemodified electrode was examined using $\mathrm{CV}$. A scan rate range of $10-100 \mathrm{mV} \mathrm{s}^{-1}$ was utilized in $5 \mathrm{mM}\left[\mathrm{Fe}(\mathrm{CN})_{6}\right]^{3-}$ $\left[\mathrm{Fe}(\mathrm{CN})_{6}\right]^{4-}$ redox probe solution, as shown in Fig. S3, whereby the oxidation and reduction potential increased with increasing scan rate. This indicated that the process was diffusioncontrolled.

A conspicuous decrease in peak current was detected after the polymerization of glutamic acid onto the AuNU/CNH/CS surface (curve c). Glutamic acid is known to have a $\mathrm{p} K_{\mathrm{a}}$ of 4.1. ${ }^{31}$ As the working $\mathrm{pH}$ used in this study was 7.4, deprotonation $\left(\mathrm{COO}^{-}\right)$of the carboxylic acid was thought to have taken place. This resulted in a charge repulsion between the negative charge of the polyglutamic acid and the negative charge of the $\mathrm{Fe}(\mathrm{CN})_{6}^{3-14-}$ redox moiety, thereby impeding the electron transfer to the working electrode. A subsequent decrease in the current signal was observed as the aptasensor was incubated with LCN-2 aptamer (curve d), indicating the successful immobilization of the aptamer onto the PGA layer by amide linkage.

\section{Optimization of the experimental conditions}

Optimization of experimental conditions was essential in order to ensure the optimal sensitivity and selectivity of the aptasensor. Therefore, factors such as $\mathrm{pH}$ of the electrolyte, aptamer concentration, aptamer reaction time and $\mathrm{LCN}-2$ binding time were studied in detail. DPV was utilised for the optimization process in consideration of its higher resolution and current sensitivity.

Most biological molecules are $\mathrm{pH}$ sensitive, and similarly this can affect the structure and properties of aptamer. The $\mathrm{pH}$ of the electrolyte for LCN-2 detection was optimized (Fig. S4A) by analyzing the current obtained when $100 \mathrm{pg} \mathrm{mL}^{-1}$ of LCN-2 was incubated in different $\mathrm{pH}$ values of electrolyte. The $\Delta I$ value, which is the change in current intensity before and after LCN-2 binding $\left(\Delta I=I_{\mathrm{LCN}-2}-I_{\mathrm{apt}}\right)$, was calculated and the optimal DPV response was found to be the highest at $\mathrm{pH} 7.4$. A decrease in performance was observed at $\mathrm{pH}$ higher and lower than 7.4, signifying that acidic and alkaline medium can affect the aptasensor activity. Hence, $\mathrm{pH} 7.4$ was selected for further experiments.

The aptamer concentration played a key role in the fabrication of the aptasensor. Therefore, the PGA/AuNU/CNH/CS modified electrode was incubated with different concentrations of LCN-2 aptamer $(0.1,1,2$, and $5 \mu \mathrm{M})$ in order to find the optimal concentration. From Fig. S4B, it can be observed that the optimum concentration was achieved at $1 \mathrm{M}$, as $\Delta I$ was at a maximum at this particular concentration. Thereafter, $\Delta I$ decreased with an increase in aptamer concentration, which may be due to overcrowding of aptamers on the electrode surface. This could hamper the conformational change that was supposed to take place upon binding of the aptamer to $\mathrm{LCN}-2$ protein, leading to inaccessibility of the redox moiety to the electrode surface.

The LCN-2 aptamer immobilization onto PGA-modified electrode was optimized by incubating the aptamer for varying amounts of time (30 min, 1, 2, $4 \mathrm{~h}$ ). The $\Delta I$ value increased up to $1 \mathrm{~h}$, but significantly decreased after incubation time of $2 \mathrm{~h}$
(Fig. S4C). Thus, $1 \mathrm{~h}$ was chosen as the optimal aptamer immobilization time.

The binding time of LCN-2 with the aptamer was a similarly crucial factor in attaining better sensitivity. To determine the optimal binding time, $100.0 \mathrm{pg} \mathrm{mL} \mathrm{mL}^{-1} \mathrm{LCN}-2$ was incubated with the aptasensor for $10,20,30,40,50$, and $60 \mathrm{~min}$, respectively. The DPV peak current was observed to increase with increasing binding time until the 30 min timepoint (Fig. S4D), but a steady decrease was observed thereafter, which may be due to the saturated level of the LCN-2-aptamer complex.

\section{Analytical performance of the aptasensor}

Following the above-mentioned procedures to determine the optimal conditions, different concentrations of $\mathrm{LCN}-2$ were incubated with the aptasensor to analyze the electrochemical response by DPV in $5 \mathrm{mM} \mathrm{Fe}(\mathrm{CN})_{6}^{3-14-}(1: 1)$ containing $0.1 \mathrm{M}$ $\mathrm{KCl}$. As observed in Fig. 4A, the DPV current increased with increasing LCN-2 concentration in the range of $0.1-100 \mathrm{pg} \mathrm{mL}^{-1}$. LCN-2 protein was positively charged at the working $\mathrm{pH} 7.4$ (pI 8.2), ${ }^{32}$ which is attributable to the increase in DPV signal as the target became bound to the immobilized aptamer, attracting more redox probes to the complex due to their anionic nature. Subsequently, the diffusion of the redox probe towards the electrode surface was improved, resulting in a lower electrontransfer barrier and increasing the DPV current peak. DPV results were converted into a calibration curve by plotting the normalized variation in redox peak current against logarithmic concentration of LCN-2. Figure 4B displays the calibration plot for the LCN-2 aptasensors in phosphate buffer, whereby the normalized redox current change was calculated using the equation $\Delta I(\%)=\left[I_{\mathrm{LCN}-2}-I_{\text {apt }}\right] / I_{\text {apt }}$, where $I_{\mathrm{LCN}-2}$ is the redox current of the LCN-2-aptamer complex and $I_{\text {apt }}$ is the redox current of the initial aptasensors. The variation in the normalized response was linear to the logarithm of $\mathrm{LCN}-2$ concentration from 0.1 to $100 \mathrm{pg} \mathrm{mL}^{-1}$, and the regression equation was identified as $\Delta I(\%)=6.978 \log C+8.43$ (where $C$ was the

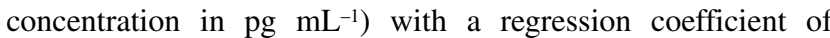
0.98865 . The limit of detection (LOD) of LCN-2 was calculated to be $10 \mathrm{fg} \mathrm{mL}^{-1}$ by using $3 \sigma / m$, (where $\sigma$ was the standard deviation of the blank and $m$ was the slope of the linear curve). ${ }^{33}$ When the concentration of LCN-2 was increased beyond $100 \mathrm{pg} \mathrm{mL}^{-1}$, plateauing of the DPV signal was observed and the signal reached saturation. This was most likely due to the saturation of the target binding sites on the aptasensor, therefore, a linear relationship could not be established with further increase in the concentration of the LCN-2 beyond $100 \mathrm{pg} \mathrm{mL}^{-1}$.

The proposed electrochemical aptasensor was compared to some of the recently developed platforms for the detection of LCN-2 as shown in Table 1. Our constructed aptasensor displayed higher sensitivity than other biosensors, including an aptasensor. Certain biosensors utilized either labelled secondary antibody or labelled aptamer, ${ }^{23,34,35}$ whereas our AuNU/CNH/CS aptasensor exploited the label-free approach, which should be more cost-effective. Furthermore, our proposed aptasensor was able to detect LCN-2 within 30 min notably one of the shortest detection times in comparison to the other methods. The low limit of detection of our aptasensor could be attributed to a couple of factors: (1) $\mathrm{CNH}$ and AuNU possessed excellent electrical conductivity and enhanced the specific surface area of the electrodes; (2) PGA modification helped to immobilize aptamers to a great extent and amplifyied the signal.

\section{The reproducibility and selectivity of the aptasensor}

The reproducibility of the aptasensor was assessed using four different LCN-2 aptasensors (Fig. 4C) and their ability to detect 
(A)

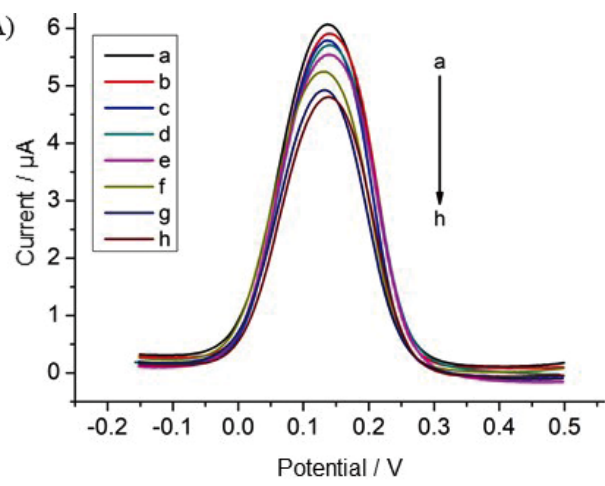

(C)

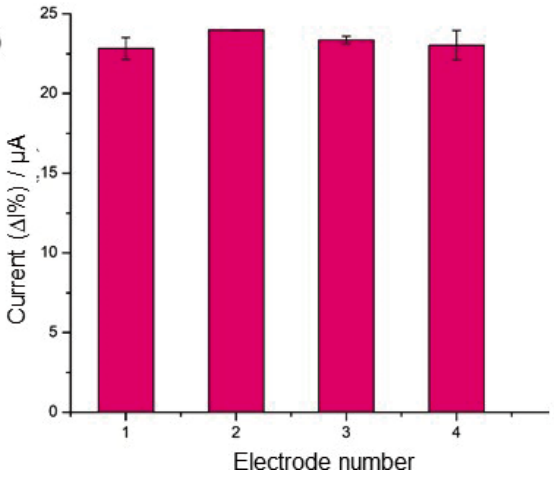

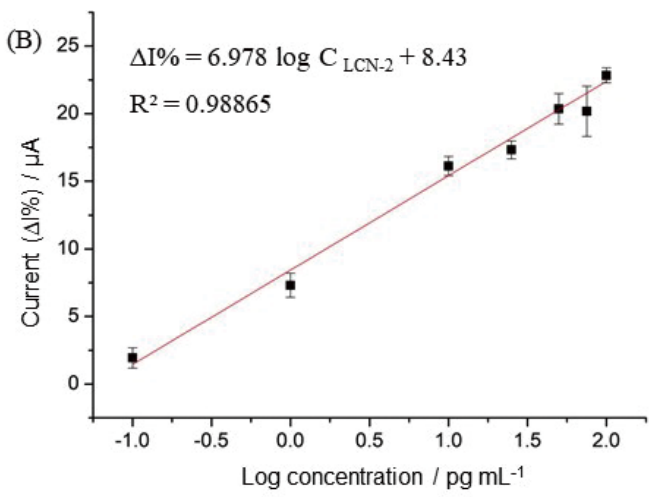

(D)

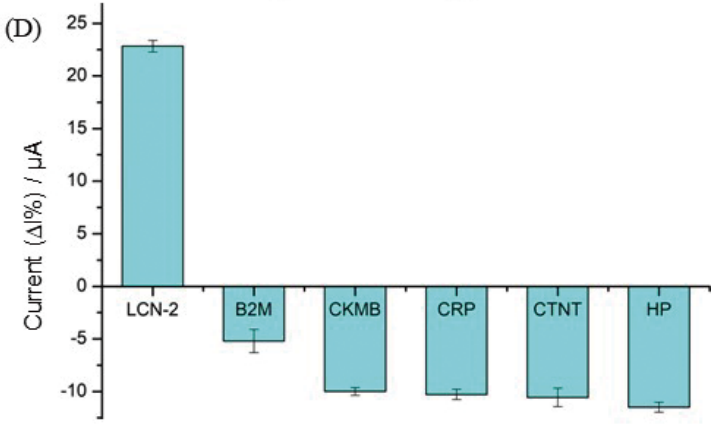

Fig. 4 (A) DPV responses of the LCN-2 aptasensor in the presence of different concentrations of LCN-2 (from a - h: 100, 75, 50, 25, 10, 1, 0.1, $0 \mathrm{pg} \mathrm{mL}^{-1}$ ), (B) calibration curve of the aptasensor from $100 \mathrm{fg} \mathrm{mL}^{-1}$ to $100 \mathrm{pg} \mathrm{mL}^{-1}$ of LCN-2, (C) reproducibility of the aptasensor with $100 \mathrm{pg} \mathrm{mL}^{-1}$ of LCN2 was studied using four different electrodes, and (D) selectivity of the LCN-2 aptasensor was analyzed with $100 \mathrm{pg} \mathrm{mL}^{-1}$ spiked concentration of $\beta 2$ microglobulin, creatine kinase MB (CKMB), C-reactive protein (CRP), cardiac troponin T (CTNT) and haptoglobin (HP).

Table 1 Comparison of the analytical performance of our proposed aptasensor with previously established methods

\begin{tabular}{|c|c|c|c|c|c|}
\hline Method & $\begin{array}{l}\text { Nanocomposite } \\
\text { modification }\end{array}$ & $\begin{array}{l}\text { Analysis } \\
\text { duration }\end{array}$ & $\begin{array}{l}\text { Linear } \\
\text { range }\end{array}$ & $\begin{array}{l}\text { Detection } \\
\text { limit }\end{array}$ & Reference \\
\hline Electrochemical immunosensor & Graphene/polyaniline (G/PANI) & $30 \mathrm{~min}$ & $50-500 \mathrm{ng} \mathrm{mL}^{-1}$ & $21.1 \mathrm{ng} \mathrm{mL}^{-1}$ & 19 \\
\hline Photoelectrochemical immunosensor & $\mathrm{ITO} / \mathrm{TiO}_{2}$ & $40 \min$ & $1.0-500.0 \mathrm{pg} \mathrm{mL}^{-1}$ & $0.6 \mathrm{pg} \mathrm{mL}^{-1}$ & 34 \\
\hline Electrochemical aptasensor & Graphene nanoplatelets (GNPs) & $1 \mathrm{~h}$ & $0.1-10 \mathrm{pg} \mathrm{mL}^{-1}$ & $0.07 \mathrm{pg} \mathrm{ml}^{-1}$ & 22 \\
\hline $\begin{array}{l}\text { Affinity peptide-incorporated } \\
\text { electrochemical biosensor }\end{array}$ & & $1 \mathrm{~h}$ & $0.0001-7.5 \mu \mathrm{g} \mathrm{mL}^{-1}$ & $1.74 \mathrm{ng} \mathrm{mL}^{-1}$ & 36 \\
\hline Electrochemical aptasensor & $\begin{array}{l}\text { Graphene oxide/gold nanoparticles } \\
\text { (GO/AuNPs) }\end{array}$ & $1 \mathrm{~h} 15 \mathrm{~min}$ & $1.0-1000.0 \mathrm{ng} \mathrm{mL}^{-1}$ & $0.3 \mathrm{ng} \mathrm{mL}^{-1}$ & 23 \\
\hline Electrochemical aptasensor & AuNU/CNH/CS & $30 \mathrm{~min}$ & $0.1-100 \mathrm{pg} \mathrm{mL}^{-1}$ & $10 \mathrm{fg} \mathrm{mL}^{-1}$ & This work \\
\hline
\end{tabular}

$100 \mathrm{pg} \mathrm{mL}^{-1}$ of LCN-2. The relative standard deviation (RSD) between electrodes was ascertained to be $2.0 \%$. The selectivity of the aptasensor was examined to determine the aptasensor's proficiency in identifying $\mathrm{LCN}-2$ from a complex sample containing similarly structured proteins. The LCN-2 aptasensor was incubated with $100 \mathrm{pg} \mathrm{mL}^{-1}$ each of $\beta 2$-microglobulin $(\beta 2 \mathrm{M})$, creatine kinase MB (CKMB), C-reactive protein (CRP), cardiac troponin T (CTNT), and haptoglobin (HP), followed by electrochemical analysis. The obtained DPV peak height was plotted as bar graphs as shown in Fig. 4D, which highlighted the high selectivity of the fabricated LCN-2 aptasensor towards LCN-2.

\section{Real sample analysis}

The practical application of the developed aptasensor was evaluated by trying to detect LCN-2 from complex biological samples such as human serum. By employing the standard addition method, LCN-2 was spiked onto a human serum sample. Different concentrations of $\operatorname{LCN}-2(0.1,10$, and $100.0 \mathrm{pg} \mathrm{mL}^{-1}$ ) were added to human serum diluted to $1000 \times$ in $10 \mathrm{mM}$ pH 7.4 PBS buffer. Electrochemical analysis was performed and the results were displayed in Table 2, and the DPV peaks obtained are shown in Fig. S4. The relative standard deviation (RSD) and recovery percentage for $0.1,10$, and $100 \mathrm{pg} \mathrm{mL}^{-1}$ of LCN-2 in $1000 \times$ diluted serum was in the range of $1.71-5.7$ and $92.7-98.3 \%$, respectively. This indicated that the proposed aptasensor could be effectively applied for the detection of LCN-2 in real serum samples. In the future, we hope to work on whole blood samples or serum samples from patients, such as those identified with acute kidney injury, rather than artificially spiking LCN-2 in control human serum. 
Table 2 Real serum sample analysis using the LCN-2 aptasensor

\begin{tabular}{ccccc}
\hline $\begin{array}{c}\text { Dilution } \\
\text { factor }\end{array}$ & $\begin{array}{c}\text { Spiked } \\
\text { concentration/ } \\
\text { pg mL }\end{array}$ & $\begin{array}{c}\text { Determined } \\
\text { concentration/ } \\
\text { pg mL }^{-1}\end{array}$ & $\begin{array}{c}\text { Recovery, } \\
\%\end{array}$ & $\begin{array}{c}\text { RSD, } \\
\%\end{array}$ \\
\hline $1000 \times$ & 0.1 & 0.098 & 98.3 & 3.1 \\
& 10 & 9.27 & 92.7 & 5.7 \\
& 100 & 95.7 & 95.7 & 1.71 \\
\hline
\end{tabular}

\section{Conclusions}

Herein, we fabricated a sensitive electrochemical aptasensor for the determination of LCN-2. A lower limit of detection was obtained by utilizing the nanocomposite AuNU/CNH/CS that was employed as to modify the working electrode. It was noted that the active electrode area increased from 2.6 to $4.1 \mathrm{~mm}^{2}$ due to the modification with AuNU/CNH/CS. Thereby, signal amplification was attained, attributable to the synergetic electrical conductivity of AuNU and $\mathrm{CNH}$. The electropolymerization of glutamic acid led to the formation of free protonated carboxyl groups on the surface of the electrode, leading to the successful immobilization of aptamers onto the electrode surface. Only a very small amount of reagents (between $2-15 \mu \mathrm{L}$ ) was required due to the utilization of a miniature screen-printed electrode, reducing the fabrication cost of the aptasensor. Under optimal conditions, the aptasensor detected LCN-2 in a concentration range from $0.1-100.0 \mathrm{pg} \mathrm{mL}^{-1}$, with a detection limit of $10 \mathrm{fg} \mathrm{mL}^{-1}$. The proposed aptasensor displayed high selectivity, good reproducibility, and acceptable sample recovery in real sample analysis. Therefore, the aptasensor is a favorable method for the determination of LCN2 from serum-based samples.

\section{Acknowledgements}

Chitra P. Kurup wishes to thank the Ministry of Education of Brunei Darussalam and Universiti Brunei Darussalam for her Ph.D. fellowship as a Bursary Award. This work was partly supported by the Universiti Brunei Darussalam's grant UBD/ RSCH/1.4/FICBF(b)/2018/010 and Brunei Research Council [Grant\# BRC-10] of Negara Brunei Darussalam.

\section{Coflict of Interest}

All authors have no financial disclosures.

\section{Supporting Information}

This material is available free of charge on the Web at http:// www.jsac.or.jp/analsci/.

\section{References}

1. J. Rashidiani, K. Eskandari, S. J. Mousavy, R. A. Taheri, and H. Kooshki, Int. J. Med. Rev., 2018, 5, 68.

2. R. Stoltenburg, C. Reinemann, and B. Strehlitz, Biomol. Eng., 2007, 24, 381.

3. M. Negahdary and H. Heli, Talanta, 2019, 198, 510.

4. Y. Seok, N. Hanun, A. Raston, and M. Bock, Biosens. Bioelectron., 2016, 76, 2.

5. M. U. Ahmed, I. Saaem, P. C. Wu, and A. S. Brown, Crit. Rev. Biotechnol., 2014, 34, 180.

6. M. Rizwan, N. Mohd-Naim, and M. Ahmed, Sensors, 2018 ,
$18,166$.

7. S. Zhao, L. Wang, T. Wang, Q. Han, and S. Xu, Appl. Surf. Sci., 2016, 369, 36.

8. S. Zhu, X. E. Zhao, J. You, G. Xu, and H. Wang, Analyst, 2015, 140, 6398.

9. F. Yang, J. Han, Y. Zhuo, Z. Yang, Y. Chai, and R. Yuan, Biosens. Bioelectron., 2014, 55, 360.

10. Z. Gao, X. Liu, C. Zhang, Z. Tang, J. Chen, and C. Yu, Int. J. Electrochem. Sci., 2018, 13, 3923.

11. S. Jafari, M. Dehghani, N. Nasirizadeh, and M. Azimzadeh, J. Electroanal. Chem., 2018, 829, 27.

12. X. Mo, Z. Wu, J. Huang, G. Zhao, and W. Dou, Anal. Methods, 2019, 11, 1475.

13. T. Vural, Y. T. Yaman, S. Ozturk, S. Abaci, and E. B. Denkbas, J. Colloid Interface Sci., 2018, 510, 318.

14. Y. Lin, K. Liu, C. Liu, L. Yin, Q. Kang, L. Li, and B. Li, Electrochim. Acta, 2014, 133, 492.

15. V. Abella, M. Scotece, J. Conde, R. Gómez, A. Lois, J. Pino, J. J. Gómez-Reino, F. Lago, A. Mobasheri, and O. Gualillo, Biomarkers, 2015, 20, 565.

16. J. Song and O. Y. Kim, Clin. Nutr. Res., 2018, 7, 1.

17. T. H. Flo, K. D. Smith, S. Sato, D. J. Rodriguez, M. A. Holmes, R. K. Strong, S. Akira, and A. Aderem, Nature, 2004, 432, 917.

18. S. M. Alwahsh, World J. Gastroenterol., 2014, 20, 1807.

19. J. Yukird, T. Wongtangprasert, R. Rangkupan, O. Chailapakul, T. Pisitkun, and N. Rodthongkum, Biosens. Bioelectron., 2017, 87, 249.

20. F. Zhang, H. Zhong, Y. Lin, M. Chen, Q. Wang, Y. Lin, and J. Huang, Microchim. Acta, 2018, 185, 327.

21. S. Song, L. Wang, J. Li, C. Fan, and J. Zhao, TrAC, Trends Anal. Chem., 2008, 27, 108.

22. N. D. Matassan, M. Rizwan, N. F. Mohd-Naim, C. Tlili, and M. U. Ahmed, in "2018 IEEE SENSORS", 2018, IEEE, $1-4$.

23. G. Aydoğdu Tiğ and Ş. Pekyardımcı, Talanta, 2020, 210, 120666.

24. M. U. Ahmed, M. M. Hossain, M. Safavieh, Y. L. Wong, I. A. Rahman, M. Zourob, and E. Tamiya, Crit. Rev. Biotechnol., 2016, 36, 495.

25. X. Hu, K. Y. Goud, V. S. Kumar, G. Catanante, Z. Li, Z. Zhu, and J. L. Marty, Sens. Actuators, B, 2018, 268, 278.

26. C. González-Vargas, N. Serrano, C. Ariño, R. Salazar, M. Esteban, and J. M. Díaz-Cruz, Chemosensors, 2017, 5, 25.

27. K. A. Lee, J. Y. Ahn, S. H. Lee, S. Singh Sekhon, D. G. Kim, J. Min, and Y. H. Kim, Sci. Rep., 2015, 5, 1.

28. M. N. S. Karaboğa and M. K. Sezgintürk, Analyst, 2019 , $144,611$.

29. M. Rizwan, D. Koh, M. Adela, and M. Uddin, Sens. Actuators, B, 2018, 255, 557.

30. M. Rizwan, S. Elma, S. A. Lim, and M. U. Ahmed, Biosens. Bioelectron., 2018, 107, 211.

31. D. P. Santos, M. V. B. Zanoni, M. F. Bergamini, A. M. Chiorcea-Paquim, V. C. Diculescu, and A. M. Oliveira Brett, Electrochim. Acta, 2008, 53, 3991.

32. S. Xu and P. Venge, Biochim. Biophys. Acta, 2000, 1482, 298.

33. X. Fu, J. He, C. Zhang, J. Chen, Y. Wen, J. li, W. Mao, H. Zhong, J. Wu, X. Ji, and C. Yu, Biosens. Bioelectron., 2019, 132, 302.

34. H. Li, Y. Mu, J. Yan, D. Cui, W. Ou, Y. Wan, and S. Liu, Anal. Chem., 2015, 87, 2007.

35. S. K. Vashist, Anal. Biochem., 2014, 446, 96.

36. C. H. Cho, J. H. Kim, D. K. Song, T. J. Park, and J. P. Park, Biosens. Bioelectron., 2019, 142, 111482. 